THEORIA ET HISTORIA SCIENTIARUM, VOL. VIII, $\mathrm{N}^{\circ} 2$

Ed. Nicolaus Copernicus University 2008

Louise Sundararajan

\title{
The Plot Thickens - or Not: Protonarratives of Emotions and the Principle of Savoring ${ }^{\star}$
}

\begin{abstract}
What are emotions good for? This paper makes the radical claim that for creative individuals at least emotional experiences may serve a similar function that Levi-Strauss attributes to death-it is "good for thought." This claim challenges the prevalent notion of emotion as "action readiness," and extends the hypothesis of emotion as "way station." To demonstrate the "way station" function of emotion, I give a phenomenological account of "protonarratives" of emotions. Protonarratives of emotions are "small stories" that are saturated with nuanced feeling tones. As such, protonarratives are more creative than full fledged narratives of emotions, partly because of their successful resistance against the latter's telos. By keeping the narrative impulses to the minimum, and by resisting the temptation of the plot to "thicken," protonarratives of emotions reduce our risk of submitting to compulsory outcomes of the narrative. For illustration, a classical Chinese poem along with the Chinese notion of aesthetic savoring are examined. This phenomenological analysis concludes with a discussion of the implications of the phenomena for creativity and theories of emotions.
\end{abstract}

Key words: narrative, protonarrative, endocept, aesthetic savoring, emotional creativity, emotion as "way station" to action.

This paper makes the counterintuitive claim that complex emotions do not necessarily require complex narrative structures; and conversely, that well developed narrative structures may in fact stifle emotional creativity. Narratives

Draft of this paper was presented at the American Psychological Association Annual Convention, 2000, Washington, DC. 
are oriented around actions with motivations that seem unambiguously goal- oriented. Protonarratives are related less to specifically goal-oriented affects, and more to background moods (Sundararajan, 2000) or „endocepts” (Arieti, 1976; Averill \& Nunley, 1992). Protonarratives allow ambiguity and exploration of multiple nuanced meanings, and thus invite us to bypass simplistic misunderstandings of intentionality of the affective life. They are less oriented toward achieving specific goals that we value, and more toward enhancing the experiencing of the value of that which we value, whatever it might be. For all these reasons, protonarrative is vital for emotional creativity. To demonstrate that a tentative attempt at narrativity is more conducive to emotional creativity than the full fledged emotional narrative, I give a phenomenological account of "protonarratives" of emotions.

"Protonarratives" are what Mark Turner refers to as "small stories," background events that are neutral in affect, such as "The wind blows clouds through the sky, a child throws a rock..." and so on. (1996, P. 13). Going to the mail box or going to work are other examples given by Philip Lewin. "[Cjohere as identifiable episodes," these events or units of activity "need not have any particular determinate meaning," says Lewin, because they are "themes that have not yet crystallized into particular experiential configuration. Only as they are incorporated into one of a number of potential narrative threads do they become determinate" (1997, p. 1, emphasis added). Put simply, protonarratives are events of everyday life that have not been emplotted into a narrative frame. To show how such barely minimum structures serve the purpose of emotions on the one hand, and challenge certain received wisdom in the field of emotion research, on the other, I present the argument in two parts: part one gives a phenomenological account of protonarratives of emotions; part two discusses the implications of the phenomena for theories of emotions.

\section{Protonarratives of Emotions: A Phenomenological Account}

Although protonarratives are neutral in affect, protonarratives of emotions are saturated with nuanced emotional tones. The boundary between the two is fluid, so is that between narrative and protonarrative. Consider the following leave taking scene at the pre-school, which lasts no more than three seconds, and seems to be "uneventful" enough to qualify as a "protonarrative":

...the father opens the door and the child enters the room, turns and looks back, father waves goodbye, and child continues on into the room as father closes the door and leaves. (Peery, 1978, p. 59) 
However, under the closer scrutiny of "frame-by-frame analysis," the researcher discerned affective undercurrents that render this "small story" a protonarrative of emotions that borders on the verge of a full-fledged narrative.

In the following I cast (in brackets) the researcher's account (Peery, 1978, p. 60) in the framework of narrative structure. A narrative structure, according to Mancuso and Sarbin (1998, p. 302), requires the following elements to make a "good" story: (1). The setting of a story [the heroine is being dropped by father at preschool]. (2). The initiating event ["The daughter, after entering the play school a few steps, turns and faces her father. .."]. (3). Goal setting [she wanted to be with the father a little longer, as evidenced by her "showing ambivalence about entering the school and leaving her father."]. (4). Descriptions of goal-directed conduct and an outcome of the conduct: ["She discontinues her leave-taking behavior and initiates an approach toward father. Father clearly indicates he is not available and will not reciprocate her approach, 'pushing' her back into the room."]. (5). An ending [ "Daughter accepts this signal without fuss and turns back, completing the leave-taking sequence."]. Here we have a "minimal narrative in a completed form" (Todorov, 1972, p. 440). "This impression of completion," writes Todorov, "is caused by a modified repetition of the initial clause; the first and the last clause will be identical but they will either have a different mood or status, for instance, or they will be seen from different points of view" (p. 440). The story begins with the heroine entering the room, and ends with her moving "more fully into the room" (Peery, 1978 , p. 60). Between these two identical clauses spans a syncope of desire-the child had temporarily relinquished her attachment to her father pursuant to the leave taking schema.

However, there is a fluid boundary between narrative and protonarrative. Should we continue with the microanalytic intent to scrutinize ever smaller units of meaning in this leave taking scene, we would arrive at protonarratives once again. Let us scale down to the duration of a fraction of a second, from Drawings of the film 3 to 4 in Peery (1978, p. 59) (see Appendix):

Beginning at Drawing 3 and continuing to Drawing 4, the daughter approaches her father slightly. At precisely the same moment (Frame 137) that the daughter begins her approach, the father takes his hand from the doorknob and raises it to the position shown in Drawing 4. This movement by the father is the beginning of a wave goodbye; but it is also very similar to the action of a policeman when stopping traffic at an intersection.

The scenario depicted in Drawing 4 (frame 142) may be considered, in the words of Blanchot (1985), "the absolutely dark moment of the plot"(p. 73), where there is "a terrible pause in which nothing stops" (p. 70). In fact, quite on the contrary, everything seems to be racing to a crescendo: the child is squarely 
facing her father, as if having something important to say; the father hastily waving his hand, obviously not in a mood to reciprocate her attention. The temptation to spin an attachment narrative is almost irresistible at this point. The story must continue. What are the father's "feelings toward his daughter"? The researcher wanted to know (Peery, 1978, p. 61): "What is his standard mode of interaction - cold and abrupt, as seen from our example, or warm and responsive in other settings? What does the daughter expect from her father? Are her emotional needs being fulfilled in their relationship?"

"The continuation? Unfortunately this isn't a story," says Blanchot in his antinarrative story, When the time comes (1985, p. 33). Story it needs not be. The scenario depicted in Drawing 4 has become a protonarrative of emotions instead.

Protonarratives of emotions are saturated with multiple nuanced feeling tones such that they may best be understood in terms of "endocepts" (Arieti, 1976; Averill \& Nunley, 1992). Endocepts are amorphous cognitive-affective structures, defined by Getz and Lubart as "idiosyncratic, multi-aspectual emotional profiles" associated with a concept or image (1998b, p. 3). The authors give as example the poetic image of "tigers selling their stripes." This image evokes a multiplicity of emotional undercurrents that can best be expressed by a conglomeration of themes such as "waste-of-beauty-andpower/abandonment-of-sophistication/pity- for-diminishment" (p. 4). Note that these thematic elements are devoid of temporal causal connections. This marks the major difference between narrative and protonarrative, a difference that coincides with that between narrative and descriptive texts. According to the Russian formalist Boris Tomashevsky, in narrative texts "causal-temporal relationships exist between the thematic elements," whereas in "descriptive" texts, "the thematic elements are contemporaneous," or arranged without "causal connections" (1965, p. 16).

Now let us reconsider Drawing 4 (see appendix):

At precisely the same moment (Frame 137) that the daughter begins her approach, the father takes his hand from the doorknob and raises it to the position shown in Drawing 4. This movement by the father is the beginning of a wave goodbye; but it is also very similar to the action of a policeman when stopping traffic at an intersection. (Peery, 1978, p. 59)

This account consists of a juxtaposition of two protonarratives-the child about to give free reign to her affective expressions, and the father making a gesture that says at once "stop" and "good bye." This scenario has the potential to become a protonarrative of emotions, if we take the following steps: a. if we don't run with the narrative impulse to emplot it into a leave-taking story, but instead pause to savor its multiple and nuanced affective undercurrents; b. if we don't sublate contradictions into a narrative unity, but instead let the incident keep its indignation and scandal; and c. if we refuse to yield to the pressure of 
the narrative telos to move hastily to problem solving, but instead slow down to circumambulate this "absolutely dark moment of the plot" (Blanchot, 1985, p. 73). Then chances are that the plot will not thicken and curdle into a leave-taking narrative, but instead fritter into a multitude of "emotional profiles" known as "endocepts." To illustrate this point, I turn to a poet who has mastered the art of protonarratives of emotions, the ninth century Chinese poet and critic Ssu-K'ung T'u (837-908). In the following paragraphs, I choose for analysis one of Ssu- -K'ung T'u's poems entitled "self-possession." My interpretation of the poem consists of only a summary account of the general consensus among the commentators. For more detailed exegesis the reader is referred to Owen (1992, pp. 311-312), and Sundararajan (1999, August).

Consider the following lines in "self-possession":

Fine words rush to the lips:

A great river stretches before our eyes. (Yip, 1969, p. 281)

In juxtaposition, without any apparent causal connections, is the image of a poet in the throes of an affective expression, and that of a river, powerful and intimidating, cutting across his path. The emotional profile of this scenario resonates well-indeed association by resonance is the way endocepts work (Getz and Lubart, 1998a)-with that of the pre-schooler in Drawing 4. In both the Chinese poem and Drawing 4, we witness the all too human drama of a certain nameless desire teetering at the edge of a boundary that it cannot and must not cross. In this "absolutely dark moment of the plot" (Blanchot, 1985, p. 73) lie the seeds of multiple emotional narratives: anger, frustration, resentment, hurt, abandonment, loss, grief, just to name a few prominent possibilities. Out of this plethora of virtual emotional narratives, one materialized for the pre-schooler-quiet resignation:

...the daughter begins turning her head away from the father and rotating her torso back into the room. By Drawing 5 she is no longer looking at her father. (Peery, 1978, p. 60)

Likewise, the poet who was about to wax eloquent suddenly fell silent, as the commentators have noted. This syncope of desire is conceptualized by the poet as a manifestation of self composure, which constitutes the title, "self- possession," and theme of his poem. The defining feature of "self-composure" seems to be successful management of emotionally stressful situations, as Owen points out rightly that "the condition is predicated on a certain tension, a self- assurance that proves itself by overcoming the threat of depression" (1992, p. 312). Here is one example of "self composure" from the poem:

Sea-winds, blue clouds,

A bright moon among isles at night. (Yip, 1969, p. 281) 
Winds sweeping across the ocean, clouds drifting in the azure sky, the bright moonlight falls silently on the isles at night. This concatenation of protonarratives evokes, according to the commentators, the emotional profile of serenity and quiet illumination, tinged with a profound sense of loneliness. These are supposedly nuanced feeling tones, or endocepts, associated with the self composure of managing the stressful situation of not being able to give free reign to one's affective expressions (Fine words rush to the lips/A great river stretches before our eyes.). But there is more to the theme of "self-composure:

No wild goose brings message here;

He is far away, traveling.

My thoughts bring him near,

As if we were together now forever. (Yip, 1969, p. 281)

In another emotionally stressful situation-not having heard from the beloved who is traveling far away-self composure consists in taking consolation from the fact that in thoughts the beloved is as close as in days gone by. Endocepts, or the emotional undercurrents, of self composure in this scenario are, according to the commentators: feelings of sadness without despair; grief without resentment.

And still more:

Green woods, among them a hut.

Setting sun, around it clear air.

Head-dress off, to stroll alone;

At times, a bird chirps. (Yip, 1969, p. 281)

A rustic hut in the green forest, the sun is setting, the air refreshingly clear, taking a walk, alone, in sheer abandonment, the only sound one hears is birds chirping from time to time. According to the commentators, this scenario highlights another emotional profile of "self composure" - feelings of serenity, solitude, and good cheer coming from a sense of inner freedom.

All this time, throughout the lengthy cogitations of "self composure" the plot fails to thicken. Instead of a narrative, we have here a veritable explosion of emotional protonarratives. Note how the above scenarios are not anchored in the temporal-causal chain of events, but instead wander freely like "an image wandering among images and drawn along with them in the monotony of a movement that appears to have no conclusion just as it had no beginning" (Blanchot, 1985, pp. 70-71). The yoke of the narrative telos is broken.

That a momentary syncope of desire should have spawned such a plethora of emotional profiles might be beyond the wildest imagination of the pre-schooler who opted for silent resignation in the wake of her failure to forestall leave taking. Neither would Mr. Jones in the following account be able to conceive of any other alternatives to his emotional narrative: 
Albert Jones, a steamfitter, was engaged in a heated quarrel with Donald Miller, a coworker, over responsibility for a botched-up job. Employing Anglo-Saxon expletives, Miller pointedly insulted Jones with a well-recognized digital gesture. Without hesitation, Jones struck Miller on the head with a fourteen-inch pipe wrench. When Jones subsequently explained his action to a police officer, he said, "I just felt the anger surging up in me and I exploded.” (Sarbin, 1989, pp. 186-187)

As Sarbin points out rightly, insults call for retaliation. "In the fast moving scenario, the form of retaliation chosen by Jones was direct assault. The protocol is silent whether Jones entertained attenuated forms of retaliation such as verbal put-down, reciprocal insult, or challenge to a duel" (Sarbin, 1989, p. 187). Sarbin further makes the important point that

It is not the case that "insult" stands alone, or that "retaliation" stands alone, or that the observations identified as anger are detachable from insult and retaliation. All these features are integral to the emplotment of an anger narrative. They are learned as a unity and perceived as a unity, (p. 187)

Indeed, as the anger narrative of Mr. Jones makes so clear, narrative unity is not without its dark side. Structurally speaking, unity has to do with "compositional motivation," which dictates that, as Tomashevsky, paraphrasing Chekhov, puts it: "if one speaks about a nail beaten into a wall at the beginning of a narrative, then at the end the hero must hang himself on that nail" (1965, p. 79, emphasis added). This may be one of the reasons why violence becomes almost ineluctable in the consummation of anger narratives. For Mr. Jones to resist the temptation of submitting to compulsory outcomes of the narrative telos. for him to reconsider other possibilities of retaliation, or even the possibility of a different emotional narrative altogether, he would do well to retrace his steps. He needs to go backward in time, to revisit that "absolutely dark moment of the plot" (Blanchot, 1985, p. 73), where multiple possibilities exist in juxtaposition, "where," as Arieti puts it so eloquently in the context of endocept, "suspense and indeterminacy reign, where simultaneity fuses with sequential time and unsuspected trans-mutations occur" (1976, p. 62).

This is exactly what the poet did in the Chinese poem, the sequence of which is tantamount to moving backward from Drawing 5 to Drawing 4 in Peery's account of the leave-taking scene, from the syncope of desire (the pre-schooler turned away from her father) to the moment of the insurmountable obstacle (the child attempted to approach the father who was not likely to reciprocate her attention). I have been quoting the Chinese poem in reverse order. The following is the poem in its original sequence:

Self-Possession

Green woods, among them a hut. 
Setting sun, around it clear air.

Head-dress off, to stroll alone;

At times, a bird chirps.

No wild goose brings message here;

He is far away, traveling.

My thoughts bring him near,

As if we were together now forever.

Sea-winds, blue clouds,

A bright moon among isles at night.

Fine words rush to the lips:

A great river stretches before our eyes. (Yip, 1969, p. 281)

In contradistinction to the narrative movement, this poem seems to proceed backward from the solution to the problem. An enchanting series of soothing and idyllic scenarios have we encountered-enjoying the solitude of an evening walk (first stanza), being united with the beloved in thought, if not in person (second stanza), and taking consolation in the serenity of quiet illumination (third stanza)-only to be perturbed at the end by an emotional dilemma, which after all is said and done about self composure, threatens to wreck our tranquility like a tenacious insomnia that no amount of halcyon imageries can ever hope to hypnotize. But why? Why does the poetic consciousness insist on doubling back to this "absolutely dark moment of the plot" (Blanchot, 1985, p. 73), turning it into "the floating festival of an instant that no longer passes" (p. 71)? The answer, I think, lies in the fact that this "absolutely dark moment of the plot" constitutes, to borrow a term from dynamic systems theory, the " bifurcating point," in which multiple future emotional narratives subsist. According to Briggs and Peat, "At each bifurcation point in our system's past, a flux occurred in which many futures existed. Through the system's iteration and amplification [or shall we say emplotting], one future [for instance, quiet resignation] was chosen and the other possibilities vanished forever [temper tantrums, crying spells, etc.]" (1989, p. 144). Might it not be that our agency and freedom are at stake, whenever we fail to complete our circumambulation around a gripping emotional protonarrative in our lives? Indeed much is at stake, as Sarbin points out, if we as "agents" "grip" too hastily "a narrative plot" (1989, p. 199). Averill and Nunley put the matter simply and straightforwardly: "Emotional creativity is about choice" (1992, p. 304). The poet says as much when he gently invites us to circumambulate once more that "absolutely dark moment of the plot," so as to prevaricate just a little longer at that single instant, where "the future is not bound to it but unbound from it" (Blanchot, 1985, p. 73).

In conclusion, small is beautiful. Protonarratives of emotions are "small stories," or minimum units of meaning, that are gravid with multiple and nuanced 
emotional undercurrents. So far as the narrative cargo is concerned, these small stories are light weight-tentative and insubstantial as if "a sub-being is trying itself out as being, " to borrow a felicitous expression from Bachelard (1969, p. 111). In the emotional landscape of our lives, these light weight stories are often found wafting with dizzying indeterminancy at the bifurcating point of an event, where in the explosion of "a large number of ever finer less intense emotional nuances" (Gray, 1979, p. 3), "all the emergences of the human" seem to be "trying itself [sic] out as being," to borrow another intuitive expression from Bachelard (1669, p. 111). Accessible perhaps only to a contemplative mind versed in the circumambulatory movement of self-reflexive thought, these small stories are indispensable to our freedom in a twofold sense of the word: freedom from compulsive outcomes of the conventional narratives of emotions, and freedom for an emotionally creative life.

\section{Implications for Theories of Emotions}

\section{The Principle of "Savoring"}

The protonarratives of emotions in Ssu-k'ung T'u's works have been understood by the poet and others as illustrative examples of the aesthetic principle of "savoring" (for details, see Sundararajan, 2004). Well known as the critic of "aesthetic savoring," Ssuk'ung T'u has written: "in my opinion we can adequately speak of poetry only in terms of making distinctions in flavors" (Owen, 1992, p. 351). In his letter to a certain Mr. Li, he expounded his theory of "flavor beyond flavor" with the following statement: "The people of Chiang-ling are incapable of making any finer distinctions. Their palate somehow falls short of perfect excellence and lacks something beyond the distinction between 'the merely sour' and 'the merely salty"' (Owen, 1992, p. 351). Translated into the framework of contemporary theories, the capacity for "savoring" or the lack thereof pertains to the notion of "emotional acuity" as conceptualized by Gelernter. Especially relevant are the following components of "emotional acuity": (1) that you are able to register subtle or nuanced emotions-to experience subtle emotional reactions - where less acute people would have no emotional reaction at all; and (2) that you are able to distinguish many elements in a subtle emotional palette, where a less acute person would distinguish the emotional equivalent of red, green, blue. (Gelernter, 1994, pp. 89-90) The parallelism between Ssu-k'ung T'u's “flavor beyond flavor" and Gelernter's analogy of color discrimination is striking: the ideal poet, according to Ssu-k'ung T'u, is able to make subtle discriminations beyond the emotional equivalent of saltiness or sourness. Owen explains: "The opposition is between gross categories that have names, and fine 
judgments for which there are no names. Furthermore, those finer gradations are learned by experience: one who knows only the gross categories can apprehend only the gross categories; to be able to recognize the finer distinctions requires the education of a sensibility" (1992, p. 352). "Exactly this kind of sensitivity lies at the root of creativity," writes Gelernter in reference to subtle discrimination of emotional nuances (1994, p. 90). By "flavor beyond flavor" Ssu-k'ung T'u also implies that the object of savoring - the poetic moods - is to be found in a realm beyond the senses ( $\mathrm{Wu}, 1963)$. In other words, poetic moods are mental constructions, rather than pre-existing entities "out there" to be discovered by the senses such as taste or smell. Paraphrasing Nietzsche - "Some souls one will never discover, unless one invents them first" (quoted in Averill \& Nunley, 1992, p. 135) - it may be said that to savor poetic moods, one has to create them first. Thus with the thesis of "flavor beyond flavor," Ssu-k'ung T'u was able to eat the cake and have it too: to take advantage of the metaphor of savoring without falling prey to its tacit implication of a pre-existing entity as the object of savoring. Developmentally "emotional acuity" belongs to the last stage of emotional development called the "nuancing and meditational phase" in William Gray's theoretical framework. According to Gray, "...the basic global emotions differentiate during child development into a large number of ever finer less intense emotional nuances, or feeling tones, of precise, sharply defined quality, and that these become patterned in a nearly infinite number of ways to constitute an emotional language for coding cognitive experience" $(1979$, p. 3). To differentiate these "ever finer less intense emotional nuances" is the task of the "nuancing and meditational phases," says William Gray: "By nuancing I mean that the feeling tone becomes subtle in its differentiation, becomes recognizable as a very particular form. Then there is the last stage, the meditational one, in which the nuanced feeling tone is held in awareness or alternately in the preconscious state..." (p. 3). This capacity to reflect upon one's feelings is referred to by Salovey, et al. (1995) as the "reflective" meta-cognition of mood that attends to moods and emotions, discriminate clearly among them, and regulate them-a capacity essential to "emotional intelligence."

In terms of information processing, savoring seems to be the affective counterpart of what Cacioppo et al. (1996) refer to as "need for cognition," which is defined as the tendency to "seek, acquire, think about, and reflect back on information to make sense of stimuli, relationship, and events in their world" (p. 198). A cognate concept is an information processing strategy referred to by Forgas (2000) as "substantive processing." Substantive processing is an "inherently constructive, generative strategy" that allows affect to "selectively prime access to, and the use of, related thoughts, ideas, memories, and interpretations" (p. 256). The Affect Infusion Model of Forgas (2000) makes the counterintuitive prediction that the more extensive the cognitive processing of 
information, the greater likelihood there is for the affectively loaded information to impact on one's thinking and action, a process referred to by Forgas (2000) as "affect infusion." Translated into the context of savoring, this counterintuitive claim becomes even more so: that extensive information processing is recruited by stimuli not more elaborate, but simpler in narrative structure - the protonarrative of emotions. This seemingly paradoxical phenomenon can be explained by the Affect Infusion Model, which predicts that substantive processing is more likely when the task is "complex, novel, or atypical" (p. 256)-the task of comprehension is rendered more challenging by protonarratives due to the latter's deficiency rather than complexity in narrative structure.

Lastly, the Chinese concept of savoring is broader in scope than the current notion of savoring in psychology. According to the theoretical framework of Bryant (1989), savoring is considered one of the perceived personal controls such as coping, avoiding, etc.; and as such it pertains to a perceived ability to appreciate and enjoy positive events, stemming from beliefs about:

a) cognitive or behavioral strategies that one can use to amplify or prolong enjoyment of positive events;

b) one's ability to anticipate future positive outcomes in ways that promote a sense of pleasure in the present;

c) one's ability to recall past positive events in ways that enhance present wellbeing; or

d) friends or relatives who can help one enjoy positive events, even if one cannot do so alone, (p. 776)

While in general agreement with Bryant's formation that stresses the ability to enjoy positive events as essential to savoring, the foregoing analysis of the protonarratives suggests additional dimensions to the phenomena of savoring:

a. savoring is the ability to appreciate and derive aesthetic pleasure from negative events as well as positive ones, and as such is characteristic of emotionally creative individuals;

b. a more felicitous theoretical framework of savoring would be "letting be" rather than "control"-the former is a receptive mode of information processing that can be masked by the more active connotations of "control." "Letting be" (see Sundararajan, 2001) refers to the awareness and acceptance of one's own emotional states, a capacity generally known as "affect tolerance" (Krystal, 1988). Affect tolerance is best described by Hartman when he refers, in the context of Wordsworth's poetry, to a consciousness that "expresses the freedom of a mind aware of itself, aware and not afraid of its moods or potentialities" (1964, p. 12). Such a frame of mind can result in a "sudden deepening" of experience, a deepening that "allows the emotion its own life and delights in new accesses of thought and feeling," writes Hartman (1964, p. 6); 
c. as we have seen, one of the preconditions of savoring seems to be attention to qualia; and

d. another precondition to savoring seems to be the ability to delay gratification, as is consistent with the "way station" theory of emotions to be expounded below. On this account, Bryant (1989) agrees-he has pointed out the importance of delayed gratification for savoring, and recommended future research to fill this vacuum in his current formulation of savoring.

\section{Implications of Savoring}

The notion of savoring is rich in implications for our understanding of emotions. From the perspective of dynamic systems theory, savoring is a good example of what Ellis (in press) refers to as "extropy," which is defined as the natural tendency for organisms to prefer higher-energy, more complex ways of maintaining homeostasis, over the lowerenergy, less complex ones. Humans world wide don't seem to rest content with the lower energy way of maintaining homeostasis by consuming food; they inevitably develop culinary art to achieve the same goal (food consumption to stay alive) at a higher, more complex level of organization. Corresponding to this two levels of organization, Ellis (in press) makes the distinction between "value achieving" and consummatory versus "value affirming" and "nonconsummatory" activities. His analysis is applicable here. Food consumption is a consummatory behavior that satisfies the basic needs of the body. Savoring in contrast is a higher level non-consummatory activity: it is not needs so much as wants/desire based. Savoring does not satisfy biological needs so much as stoke the desire, which seeks stimulation rather than consummation. From the perspective of basic needs, the "value affirming" function of taste serves the "value achieving" goal of consuming the foods deemed valuable by taste. At the higher, more complex level of organization as is the case with savoring, however, the "value affirming" function of taste has become an end in itself, such that the tight coupling, at the lower level of organization, between perception (taste) and action (food consumption) is loosened. This observation has implications for theories of emotion.

Phenomenologists who give priority to the value affirming function of emotions-for instance, Heidegger's (1962) notion of the world-disclosing function of mood (see also Smith, 1981)-are exceptions to the rule. Psychological theories of emotions in general tend to privilege the action potential of emotions. For instance, Oatley proposes that "Emotions function in the management of action when all the consequences of such action cannot be fully foreseen" (1992, p. 24). He goes on to say that "emotions set the cognitive and bodily systems into certain modes of readiness for small sets of action patterns that have evolved to cope 
with specific kinds of juncture as they occur" (p. 36). A sociological variant of the theme is Sarbin's (1986) claim that emotions are stereotypical patterns of behaviors referred to as "identity roles"-roles such as the angry victim enacted by Mr. Jones-that help to maintain and enhance a person's identity and values. Against this received wisdom in the field, the notion of savoring puts a premium on the value-affirming function of affective perception over the value-achieving function of action. Supporting evidence for the importance of savoring can be gleaned from Ramachandran and Hirstein's (1999) research on qualia and consciousness. The authors have shown that qualia are the interface between perception and action, such that: "sensations which are qualia-ladden afford the luxury of choice" (p. 92). This is consistent with the findings of other researchers (see Clore \& Parrott,1991; Robinson, 1998) that suggest that the function of subjectively experienced affect is to recruit controlled processing, such as making choices, and finding alternatives. These observations tempt us to reopen the question: What's emotion good for? And the foregoing analysis of savoring suggests a seemingly radical answer: for creative individuals at least emotional experiences may serve a similar function that Levi-Strauss attributes to death- it's "good for thought." Of course, thought in turn is good for action, so this conclusion is not as radical as it may sound at first blush. But the mediated connection between emotion and action is what aesthetic savoring seems to take advantage of, and what the action oriented theories of emotions tend to overlook.

In the final analysis, protonarratives of emotions challenge certain received notions about emotions and confirm others. The phenomena presented in the foregoing analysis challenge the prevalent notion of emotion as action readiness (Frijda, 1986). The actionoriented theoretical framework is incapable of answering the following question: What is the functional utility of parading a wide spectrum of action-readiness, as Ssu-k'ung T'u was wont to do, rather than acting on a specific one, as Mr. Jones did only too well? This question can be adequately addressed by Scherer's formulation of emotion as "way station" to action. Scherer (1994) has suggested that the evolutionary function of emotion is to decouple a stimulus from a response. In pre-emotional organisms (roughly at the level of fish or amphibians) behavior is regulated by reflexes and fixed action patterns, whether innate or learned. As we ascend the phylogenetic scale, the range of environments to which organisms can adapt becomes increasingly complex. This, according to Scherer (1994), presents an "engineering" problem-how to preserve the advantages of a quick and energetic response to potentially important events while at the same time introducing the flexibility needed to adapt to a range of environments. The solution to this problem, Scherer suggests, is the emotions. Emotions introduce a latency period that allows for a continuous appraisal and reappraisal of the situation and, concomitantly, the organization of appropriate responses. This process reaches its highest level in humans, which are the most 
emotional of species. And among humans, we may add, emotionally creative individuals can be expected to capitalize on this "way station" function of emotions by constructing and savoring protonarratives of their affective experiences.

\section{References}

Arieti, S. (1976). Creativity: The magic synthesis. New York: Basic Books.

Averill, J. R. \& Nunley, E. P. (1992). Voyages of the heart: Living an emotionally creative life. New York: Free Press.

Bachelard, G. (1969). The poetics of reverie (Daniel Russell, Trans.). Boston: Beacon.

Blanchot, M. (1985). When the time comes (Lydia Davis, Trans.). Barrytown, NY: Station Hill. (French edition 1951)

Briggs, J. and Peat, F. D. (1989). Turbulent mirror : an illustrated guide to chaos theory and the science of wholeness. New York: Harper \& Row.

Bryant, F. B. (1989). A four factor model of perceived control: Avoiding, coping, obtaining, and savoring. Journal of Personality, 57 (4), 773-797.

Clore, G. L., \& Parrott, W. G. (1991). Moods and their vicissitudes: Thoughts and feelings as information. In J. P. Forgas (Ed.), Emotion and social judgements. International Series in experimental social psychology (pp. 107-123). Oxford, UK: Pergamon.

Cacioppo, J. T., Petty, R. E., Feinstein, J. A., \& Jarvis, W. B. G. (1996). Dispositional differences in cognitive motivation: The life and times of individuals varying in need for cognition. Psychological Bulletin, 119 (2), 197-253.

Ellis, R. D. (In press). Non-Consummatory Motivations: Extropy and "life wish" in the self-organization of emotion. Forthcoming in Theoria et Historia Scientarium.

Forgas, J. P. (2000). Feeling and thinking. Cambridge: Cambridge University.

Frijda, N. H. (1986). The emotions. Cambridge: Cambridge University.

Gelernter, D. (1994). The muse in the machine. New York: Macmillan.

Getz, I. \& Lubart, T. I. (1998a). The emotional resonance model of creativity: Theoretical and practical extensions. In S. W. Russ (Ed.), Affect, creative experience, and psychological adjustment (PP. 41-56), Philadelphia, PA: Brunner/Mazel.

Getz, I. \& Lubart, T. I. (1998b, August). Creative interpretation: An emotion-based model inspired by artists' theories. Paper presented at the $106^{\text {th }}$ Annual Convention of the American Psychological Association, San Francisco.

Gray, W. (1979). Understanding creative thought processes: An early formulation of the emotional-cognitive structure theory. Man-Environment Systems, 9 (1), 3-14.

Hartman, G. H. )(1964). Wordswprtli's poetry. New Haven: Yale University.

Heidegger, M. (1962). Being and Time (J. Macquarrie \& E. Robinson, Trans.). New York: Harper \& Row.

Krystal, H. (1988). Integration \& self-healing/Affect, trauma, alexithymia. Hillsdale, NJ: The Analytic Press.

Lewin, P. (1997). The ethical self in the play of affect and voice. In After Post-Modernism Conference, Focusing Institute, at http://www.focusing.org/Lewin.html. 
Mancuso, J. C. and Sarbin, T. R. (1998). The narrative construction of emotional life/ Developmental aspects. In M. F. Mascolo and S. Griffin (Eds.), What develops in emotional development? (Ch. 12). New York: Plenum.

Owen, S. (1992). Readings in Chinese literary thought. Cambridge, MA: Harvard University.

Oatley, K. (1992). Best laid schemes/The psychology of emotions. Cambridge: Cambridge University.

Peery, J. C. (1978, Fall). Magnification of affect using frame-by-frame film analysis. Environmental Psychology and Nonverbal Behavior, 3 (1), 58-61.

Ramachandran, V. S., \& Hirstein, W. (1999). Three laws of qualia. In S. Gallagher, \& I. Shear (Eds. ), Models of the self (pp. 83-111). New York: Imprint Academic.

Robinson, M. D. (1998). Running from William James' bear: A review of preattentive mechanisms and their contributions to emotional experience. Cognition and Emotion, 12 (5), 667-696.

Salovey, P, Mayer, J. D., Goldman, S. L., Turvey, C., \& Palfai, T. P. (1995). Emotional attention, clarity, and repair: Exploring emotinal intelligence using the Trait Meta- Mood Scale. In J. W. Pennebaker, Emotion, Disclosure, and health (pp. 125-154). Washington, D. C.: American Psychological Assn.

Sarbin, T. R. (1986). Emotion and act: Roles and rhetoric. In R. Harre (Ed.), The social construction of emotions (pp. 83-97). Oxford: Blackwell.

Sarbin, T. R. (1989). Emotions as narrative emplotments. In M. Packer \& R. Addison (Eds.), Entering the circle: Hermeneutical studies in psychology (ch 7). Albany: State University of New York.

Scherer, K. (1994). Emotion serves to decouple stimulus and response. In P. Ekman \& R. J.

Davidson (Eds.), The nature of emotion: Fundamental questions (pp. 127-130). New York: Oxford University Press.

Smith, Q. (1981). On Heidegger's theory of moods. The Modern Schoolman, LVIII (4), 211235.

Sundararajan, L. (1999, August). "Tracing Emotions Daintily"-Emotional Creativity in Chinese poetics. In L. Sundararajan (chair), Emotional Innovations: Intelligence and Creativity in a New Key. Symposium conducted at the 107, ${ }^{\text {h }}$ Annual Convention of the American Psychological.Association, Boston.

Sundararajan, L. (2000). Background-mood in emotional creativity: A microanalysis. Consciousness and Emotion, 1 (2), 227-243.

Sundararajan, L. (2001). Alexithymia and the reflexive self: Implications of congruence theory for treatment of the emotionally impaired. The Humanistic Psychologist, 29, 223248.

Sundararajan, L. (in press). Twenty-four poetic moods: Poetry and personality in Chinese aesthetics. Creativity Research Journal, 16, (2 \& 3), 201-214.

Todorov, T. (1972). Structural analysis of narrative. In L. Lipking and A. W. Litz, Modern literary criticism, 1900-1970 (pp. 436-441). New York: Atheneum.

Tomashevsky, B (1965). Thematics. In Lemon, L. T. \& Reis, M. J. (Trans.), Russian formalist criticism, four essays (pp. 62-95). Lincoln: University of Nebraska.

Turner, M. (1996). The literary mind/The origins of thought and language. New York: Oxford University. 
Wu, Tiao-kung. (1963). Ssuking Tu's poetic criticism. Chinese Literature, 7, 78-83. Yip, Wai-lim, trans. (1969). Selections from „The twenty-four orders of poetry.” Stony

Brook, 3/4, 280-287.

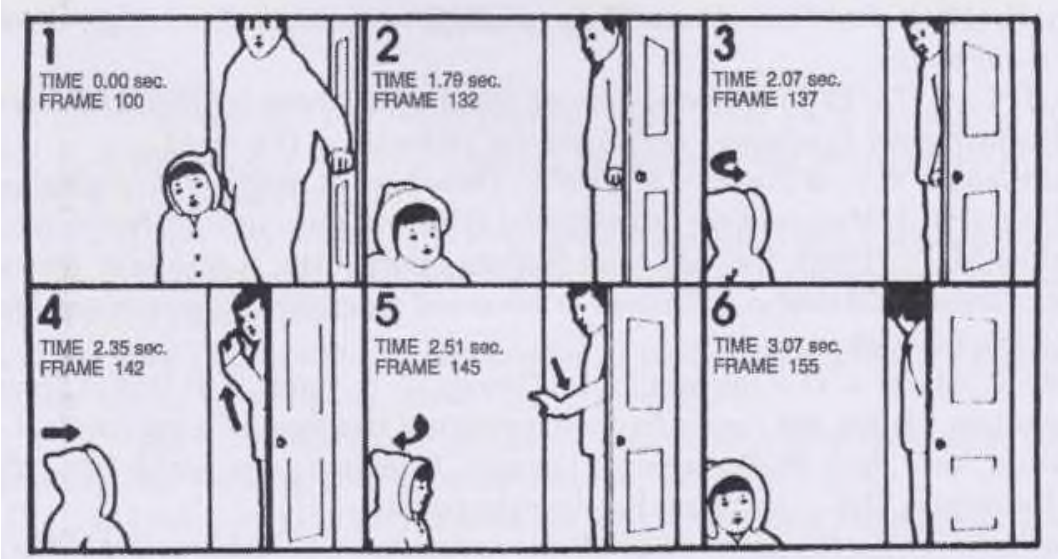

Figure 1 in J. Craig Peery, Magnification of affect using frame-by-frame film analysis (p. 59), reproduced with permission from Journal of Nonverbal Behavior. 